\section{Through the Learner's} Lens: Eye-Tracking Augmented Debriefing in Medical Simulation

\section{Setting and Problem}

Effective debriefing is a critical component of simulation-based education, and experts agree that a significant proportion of learning in simulation occurs during the debrief. Traditional debriefing techniques like the Plus Delta or Advocacy/Inquiry approaches are useful, but they may be limited if the full picture of the decision-making processes that occurred during the simulation is not known. Memory science suggests that it is unlikely that residents can accurately and consistently recall specific situational cues that precede clinical decision-making. For this reason, the rationale for clinical decision-making may be difficult to unpack and may be susceptible to recall biases (eg, hindsight bias). Although bird's eye video could provide context, it too does not allow for visualization of the clinical context from the resident's perspective. To get inside the head of a trainee and provide more targeted feedback, we propose a novel method of cued retrospective debriefing augmented by eye-tracking technology.

\section{Intervention}

Emergency medicine residents were outfitted with mobile eye-tracking glasses during 2 resuscitationbased objective structured clinical examinations (OSCEs) in a high-fidelity patient simulation laboratory. Twenty-two residents participated over the course of 2 examinations; 13 residents completed both examinations. The eye-tracking glasses recorded the simulated encounters from a first-person perspective while measuring pupil position at $50 \mathrm{~Hz}$. This allowed for the creation of a video that showed the simulated encounters from the resident's perspective, with a superimposed gaze indicator that displayed where the resident was looking at all times.

After completion of the OSCE, residents participated in a traditional faculty-led debrief. Immediately

DOI: http://dx.doi.org/10.4300/JGME-D-17-00827.1
TABLE

Summary of Emergent Themes

\begin{tabular}{|c|c|}
\hline Theme & Example Quote \\
\hline $\begin{array}{l}\text { New insights and reflective } \\
\text { thinking }\end{array}$ & $\begin{array}{l}\text { "I think it's a good way to } \\
\text { do a lot of self-reflection, } \\
\text { a lot of ways to do real- } \\
\text { time assessment. Like, I } \\
\text { can see what I was } \\
\text { thinking at the same } \\
\text { time." (P19) }\end{array}$ \\
\hline $\begin{array}{l}\text { Identifying errors from video } \\
\text { review }\end{array}$ & $\begin{array}{l}\text { "Yeah, I sort of saw where I } \\
\text { got distracted and led } \\
\text { off-course better than I } \\
\text { think I would have } \\
\text { otherwise, had we not } \\
\text { debriefed and seen } \\
\text { where I started to focus } \\
\text { on things that were } \\
\text { perhaps more distracting } \\
\text { than anything else." (P11) }\end{array}$ \\
\hline $\begin{array}{l}\text { Added value of eye-tracking } \\
\text { technology }\end{array}$ & $\begin{array}{l}\text { "And I love good feedback } \\
\text { and different molds of } \\
\text { doing this, and this is an } \\
\text { incredible tool. Like I've } \\
\text { never seen the ability to } \\
\text { see where somebody's } \\
\text { looking . . . it's an } \\
\text { amazing tool for } \\
\text { identifying cognitive } \\
\text { overload." (P18) }\end{array}$ \\
\hline
\end{tabular}

afterward, each resident met with a separate faculty debriefer who led an individualized debrief that was augmented by review of the residents' own eyetracking videos. The debriefer played the videos back to each resident, pausing them at critical junctures and inquiring about each resident's decision-making and crisis resource management decisions. Individualized feedback, which invited the resident to compare and contrast his or her decision-making with the decision-making of an expert, was provided based on the ensuing discussion.

Each resident was then asked to compare the utility of the traditional debriefing technique to the novel debriefing technique with an audio-recorded semistructured interview. Over the course of 2 OSCEs, interviews from 35 individual debriefings (each based on two 10-minute simulation scenarios) were analyzed using a thematic emergent design through a phenomenological lens.

This study received approval from the Queen's University Research Ethics Board. All participants provided informed consent.

\section{Outcomes to Date}

Three main themes emerged from the qualitative analysis. See the TABLE for a list of themes and 
example quotes. All residents reported that the cued retrospective debriefing augmented by eye-tracking was useful for their learning. This novel approach encouraged residents to reflect on their performance, leading them to critique responses to specific situational cues and to identify new insights into their performance. Many residents reported that these insights were missed during the initial traditional debrief and only came to light by virtue of the eye-tracking video review.

Though primarily used in the research realm because of financial constraints, the cost of eyetracking technology is quickly decreasing. This will allow medical educators to harness the benefits of this technology in simulation debriefing where it has the potential to enrich the process of learning.

Adam Szulewski, BSc, MD, FRCPC, MHPE Assistant Professor, Department of Emergency Medicine, Queen's University, Kingston, Ontario, Canada

Heather Braund, BSc, MEd

Doctoral Student, Faculty of Education, Queen's University

\section{Rylan Egan, PhD}

Director, Office of Health Sciences Education, Queen's University

\section{Andrew K. Hall, MD, FRCPC, MMEd}

Assistant Professor, Department of Emergency

Medicine, Queen's University

Jeffrey Damon Dagnone, MD, FRCPC, MMEd Associate Professor, Department of Emergency Medicine, Queen's University

\section{Andreas Gegenfurtner, $\mathrm{PhD}$}

Researcher, Technische Hochschule Deggendorf, Deggendorf, Germany

\section{Jeroen J. G. van Merrienboer, PhD}

Professor, Department of Educational Development and Research, Faculty of Health, Medicine and Life Sciences, Maastricht University, Maastricht, Netherlands

Corresponding author: Adam Szulewski, BSc, MD, FRCPC, MHPE, Kingston General Hospital, 76 Stuart Street, Kingston, ON K7L 2V7 Canada, 613.549.6666, aszulewski@qmed.ca

\section{A Daily Dose of Humanities}

\section{Setting and Problem}

Incorporating humanities into medical education can promote physical examination skills, humanistic attributes, and professional conduct. Medical humanities programs are typically offered as separate/elective coursework outside of existing curricular elements and are more common in undergraduate than graduate medical education programs. Our group recently demonstrated that such humanities coursework results in preserved empathy among medical students. This residency-based pilot study sought to determine the feasibility of including the humanities in an existing framework within the context of clinical training rather than through additional coursework.

\section{Intervention}

On the inpatient general medicine service at a tertiary care teaching hospital in Spokane, Washington, daily attending rounds begin with a brief discussion of a piece of art. The medicine team consists of a senior internal medicine resident, 2 junior residents, and 1 to 2 medical students. Before patient care issues are discussed, 1 team member shares a piece of art, which is a springboard for group discussion and personal reflection. On the first day of the rotation, the attending physician models the activity for the group. The art modality is determined by the attending physician and his or her particular interest, which is typically 1 of 3 forms: popular music, art/photography, or literature. Once the art form is presented, team members share their thoughts about what they hear or see in the piece and how it relates to medicine or to them personally, with an attending physician facilitating the discussion. The person who brings in the art is the last person to speak. The exercise takes 5 to 10 minutes. Residents are exposed to several attending physicians during the course of their training, thus ensuring a broad exposure to art forms and different facilitated discussion styles.

\section{Outcomes to Date}

The use of humanities at the beginning of inpatient rounds has been enthusiastically accepted and 